\title{
Use of the Arbuscular Mycorrhizal Fungus Glomus intraradices as Biological Control Agent of the Nematode Nacobbus aberrans Parasitizing Tomato
}

\author{
Nicolás Marro ${ }^{1 *}$, Paola Lax ${ }^{2}$, Marta Cabello ${ }^{3}$, Marcelo Edmundo Doucet ${ }^{2}$ and Alejandra \\ Gabriela Becerra ${ }^{1}$ \\ ${ }^{1}$ Laboratorio de Micología; Instituto Multidisciplinario de Biología Vegetal; CONICET- Universidad Nacional de \\ Córdoba; Córdoba - Argentina. ${ }^{2}$ Instituto de Diversidad y Ecología Animal (CONICET-UNC) y Centro de Zoología \\ Aplicada, Facultad de Ciencias Exactas, Físicas y Naturales, Universidad Nacional de Córdoba, Argentina. \\ ${ }^{3}$ Instituto Spegazzini, Facultad de Ciencias Naturales y Museo, Buenos Aires, Argentina
}

\begin{abstract}
The plant-parasitic nematode Nacobbus aberrans is an endoparasite that induces gall formation in the roots and causes severe losses to diverse crops. Some populations of this nematode show preference for certain hosts, revealing the existence of "races/groups" with different behaviour and making nematode management difficult. A possible biological control alternative to reduce the damage caused by this species may be the use of arbuscular mycorrhizal fungi (AMF). In the present work, the effect of Glomus intraradices on tomato plants inoculated with the nematode at transplanting and three weeks later was tested. At 60 days, the following parameters were estimated: percentage of AMF colonization, root and aerial dry weight, number of galls and egg masses, and reproduction factor (RF=final population/initial population) of $\mathrm{N}$. aberrans. AMF colonization was higher in the presence of the nematode. The use of AMF favoured tomato biomass and reduced the number of galls and RF on the plants inoculated with the nematode at transplanting.
\end{abstract}

Key words: arbuscular mycorrhiza, false root-knot nematode, microbiological control, plant protection

\section{INTRODUCTION}

Some species of plant-parasitic nematodes can cause severe damage to numerous crops. They attack mainly the root system. As a consequence, the plant loses its capacity to take up water and nutrients, with likely reductions in the growth and yield (Talavera et al. 2001). Nacobbus aberrans (Thorne) Thorne and Allen is a sendentary endoparasite that causes histological alterations to the root tissues, inducing gall formation. Because the galls are very similar to those produced by Meloidogyne spp. (root-knot nematode), $N$. aberrans is also known as the "false root-knot nematode". The nematode is native to the Americas (Sher 1970), and is present in Argentina, Bolivia, Chile, Ecuador, Mexico, Peru, and the United States. It is a species of quarantine importance (Karssen and den Nijs 2001) that has a wide host range. Parasitized plants can show poor development, chlorotic leaves, wilting and smallsized fruits (Manzanilla-López et al. 2002). $N$. aberrans was first detected in north-western Argentina in 1977 parasitizing several crops and some weeds (Costilla et al. 1977). At present, it has a wide distribution (Doucet and Lax 2005). In Córdoba province, it causes severe damage to tomato (Solanum lycopersicum L.) and pepper

*Author for correspondence: marronicolas@ hotmail.com 
(Capsicum annuит L.), both crops being grown in greenhouses (Lax et al. 2011).

Arbuscular mycorrhizal fungi (AMF) establish a symbiotic relationship with most plant species (Wang and Qiu 2006). These fungi increase host development and tolerance against several soil pathogens, such as plant-parasitic nematodes. AMF facilitate uptake of the nutrients, mainly of phosphorus (Borowicz 2001), increasing plant vigor (Azcón-Aguilar and Barea 1996). In addition, AMF affects the nematodes by altering root exudates (Graham and Menge 1982) or by producing phytoalexins in the root, such as glyceollin, which could have nematicidal effects (Morandi 1996). Although possible mechanisms have been proposed to explain the reduction of harmful nematodes in the presence of AMF, they remain a matter of speculation (Elsen et al. 2001; Elsen et al. 2003).

The interaction between the AMF and Meloidogyne spp. in the plants of economic importance has been widely documented, with records of reduction in reproduction (Jaizme-Vega et al. 1997; Castillo et al. 2006), number of second-stage juveniles (J2) in the soil (Shreenivasa et al. 2007; Gómez et al. 2008) and number of egg masses (Da Silva Sousa et al. 2010). The above works also reported a lower number of galls induced by these nematodes.

Studies on $N$. aberrans-AMF interaction are scarce (Gardezi et al. 1995; Lax et al. 2011). A reduced number of galls was detected in tomato plants colonized by Glomus spp. (Gardezi et al. 1995). Tomato plants colonized by $G$. intraradices Schenck and Smith and further inoculated with an Argentine population of the nematode showed a reduction in the multiplication of the parasite (Lax et al. 2011). N. aberrans populations can behave in a different way on a single plant or a range of hosts; hence, the existence of "races/groups" within the species is considered (ManzanillaLópez et al. 2002). Such physiological variability hinders the agricultural damage produced by the nematode. Therefore, studies with new populations from different geographical regions are necessary. The aim of the present work was to evaluate the effect of $G$. intraradices on a new and different Argentine population of $N$. aberrans and on tomato plant biomass.

\section{MATERIALS AND METHODS}

A population of $N$. aberrans from the locality of Río Cuarto (Río Cuarto department, Córdoba province, Argentina) was used for this study. Nematodes were multiplied on tomato cultivar Platense under greenhouse conditions. Egg masses of the nematode were extracted from the infected plants and placed in Petri dishes containing sterile water. They were maintained at room temperature to allow hatching; then, mobile J2s were recovered.

Spores and roots colonized by $G$. intraradices (origin: La Plata, Herbario Spegazzini (LPS), Tierra del Fuego 28) were used for the study. The fungus was propagated on leek (Allium porrum L.) in the pots containing a mixture of sterile perlite and vermiculite (1:1) for six months. After this period, roots $(0.25 \mathrm{~g})$ were chopped into $1-\mathrm{cm}$ long segments to determine the mycorrhizal colonization (Phillips and Hayman 1970) and quantify the AMF (Giovannetti and Mosse 1980). To obtain the spores, $G$. intraradices was propagated on alfalfa (Medicago sativa $\mathrm{L}$.) plants for six months in the pots containing the same substrate as used for leek and fed with a nutrient solution three times a week (Cabello 1997). After that, a sample $(5.0 \mathrm{~g})$ of the perlite-vermiculite mixture was extracted to quantify the number of spores using the wet sieving and decanting technique (Gerdemann and Nicolson 1963).

The seeds of tomato Platense were surfacesterilized with $10 \% \mathrm{NaClO}$ for five minutes and placed to germinate in the trays containing a mixture of sterile soil and sand (3:1). The physical and chemical characteristics of the soil were as follows (\%): silt 23, clay 20, sand 57, organic matter 13.2, $\mathrm{N} 0.5$, and $\mathrm{P} 21 \mathrm{mg} / \mathrm{Kg}$; $\mathrm{pH} 5.2$ Onemonth-old seedlings were transplanted to the containers $(20 \mathrm{~cm}$ long $\times 4 \mathrm{~cm}$ wide, with a capacity of $190 \mathrm{~g}$ of soil). The experimental design consisted of six treatments with six replicates each: 1) non-inoculated plants (Control), 2) plants inoculated with $G$. intraradices at transplanting (AMF T0), 3) plants inoculated with $N$. aberrans at T0 (NEM T0), 4) plants inoculated with $N$. aberrans and $G$. intraradices at T0 (AMF T0 + NEM T0), 5) plants inoculated with $N$. aberrans three weeks after transplanting (NEM T3), 6) plants inoculated with $G$. intraradices at $\mathrm{T} 0$ and with $N$. aberrans three weeks after transplanting (AMF T0 + NEM T3). 
At transplanting, the container was filled to twothird of its capacity with the substrate. In the treatments with $N$. aberrans, the initial population (Pi) of the nematode $(100 \mathrm{~J} 2 / 1.5 \mathrm{~mL}$ of sterile water) was deposited on the roots. In the plants treated with AMF, a homogeneous layer of the fungal inoculum $(0.25 \mathrm{~g}$ of leek roots with $62.5 \%$ colonization and $5.0 \mathrm{~g}$ of the perlite-vermiculite mixture containing 1800 spores) was deposited; tomato seedlings were placed on the substrate and then roots were covered with the substrate. Plants were grown in a greenhouse $\left(24 / 18^{\circ} \mathrm{C}\right.$ day/night, $16 / 8 \mathrm{~h}$ day/night photoperiod). After 60 days, the plants were removed and biomass (aerial and root dry weight) was measured. The number of galls induced by the nematode was counted. Egg masses were extracted, counted and placed in a $1 \% \mathrm{NaClO}$ solution for 4 min to count the eggs (Hussey and Barker 1973). The soil of each plant was processed using the centrifugal-flotation technique (Jenkins 1964) to obtain vermiform stages. Final population (Pf) was estimated for each replicate by adding the number of eggs and nematodes extracted from the soil. Pf value was used to calculate the Reproduction Factor $(\mathrm{RF}=\mathrm{Pf} / \mathrm{Pi})$. In addition, for all the treatments, roots were stained and total mycorrhizal colonization was quantified, following the previously mentioned techniques.

Normality and homogeneity assumptions were confirmed for all the variables before statistical analyses. An ANOVA was performed to detect the differences among the treatments $(p<0.05)$. The DGC multiple comparison test (test of Di Rienzo, Guzmán and Casanoves) was applied (Infostat 2001).

\section{RESULTS}

Both plant growth parameters showed significant differences among the treatments (Table 1). Aerial biomass was higher in AMF T0 and NEM T0 than in the control. Root biomass increased in AMF T0 compared to non-inoculated plants and NEM T0. Plants of the treatment AMF T0 + NEM T0 showed a greater aerial and root biomass than the control and NEM T0. No significant differences were observed between the two treatments inoculated with $N$. aberrans at T3 with respect to the control.

Mycorrhizal colonization of $G$. intraradices was observed only in those treatments that were inoculated with the fungus. Root systems of tomato showed external and intracellular aseptate hyphae, terminal arbuscules, intracellular vesicles and coils (Fig. 1). Plants parasitized with the nematode showed a significant increase in mycorrhizal colonization (Table 2).

Table 1 - Dry weight of tomato (cultivar Platense) inoculated with Glomus intraradices (AMF) and Nacobbus aberrans (NEM).

\begin{tabular}{ccc}
\hline Treatment & Aerial part $(\mathbf{g})$ & Root $(\mathbf{g})$ \\
\hline Control & $0.43 \pm 0.13 \mathrm{c}^{1}$ & $0.24 \pm 0.09 \mathrm{~b}$ \\
AMF T0 & $0.89 \pm 0.12 \mathrm{a}$ & $0.45 \pm 0.15 \mathrm{a}$ \\
NEM T0 & $0.63 \pm 0.2 \mathrm{~b}$ & $0.19 \pm 0.03 \mathrm{~b}$ \\
AMF T0 + NEM T0 & $0.77 \pm 0.13 \mathrm{a}$ & $0.46 \pm 0.14 \mathrm{a}$ \\
NEM T3 & $0.44 \pm 0.15 \mathrm{c}$ & $0.12 \pm 0.02 \mathrm{~b}$ \\
AMF T0 + NEM T3 & $0.34 \pm 0.04 \mathrm{c}$ & $0.14 \pm 0.06 \mathrm{~b}$ \\
\hline
\end{tabular}

Values are mean and standard deviation of six replicates per treatment. ${ }^{1}$ Different letters between rows indicate significant differences $(p<0.05)$. AMF $\mathrm{T} 0=G$. intraradices inoculated at transplanting; NEM T0 $=N$. aberrans inoculated at transplanting; NEM T3 $=N$. aberrans inoculated three weeks after transplanting.

Table 2 - Percentage of mycorrhizal colonization of $G$. intraradices (AMF) in tomato (cultivar Platense) inoculated with Nacobbus aberrans (NEM).

\begin{tabular}{cc}
\hline Treatment & Colonization (\%) \\
\hline AMF T0 & $22.87 \pm 6.81 \mathrm{~b}^{1}$ \\
AMF T0 + NEM T0 & $35.89 \pm 2.8 \mathrm{a}$ \\
AMF T0+ NEM T3 & $43.96 \pm 9.42 \mathrm{a}$ \\
\hline
\end{tabular}

Values are mean and standard deviation of six replicates per treatment. ${ }^{1}$ Different letters indicate significant differences $(p<0.05)$. AMF T0 $=G$. intraradices inoculated at transplanting; NEM T0 $=N$. aberrans inoculated at transplanting; NEM T3 $=N$. aberrans inoculated three weeks after transplanting.

All the tomato plants inoculated with $N$. aberrans J2s presented galls and egg masses generated by the nematode (Fig. 2). In NEM T0, the mean value of number of galls and RF was significantly higher than in the remaining treatments (Table 3). No significant differences were observed for number of egg masses.

Table 3 - Effect of the application of Glomus intraradices on tomato infected by Nacobbus aberrans.

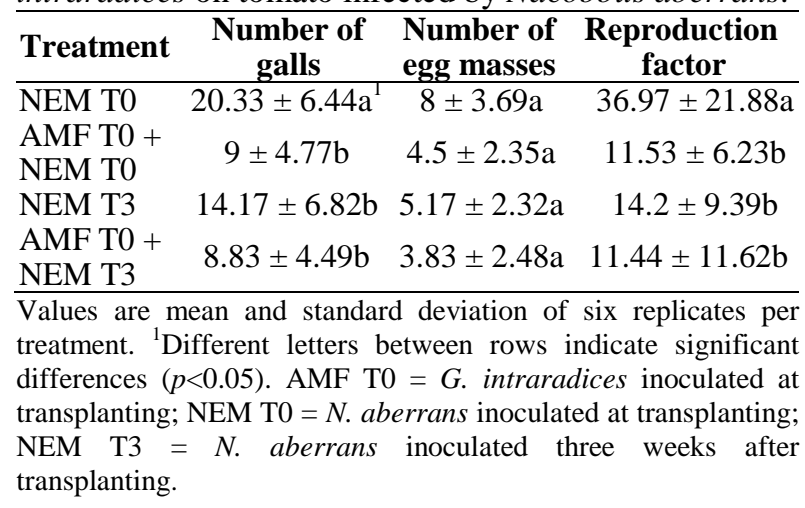



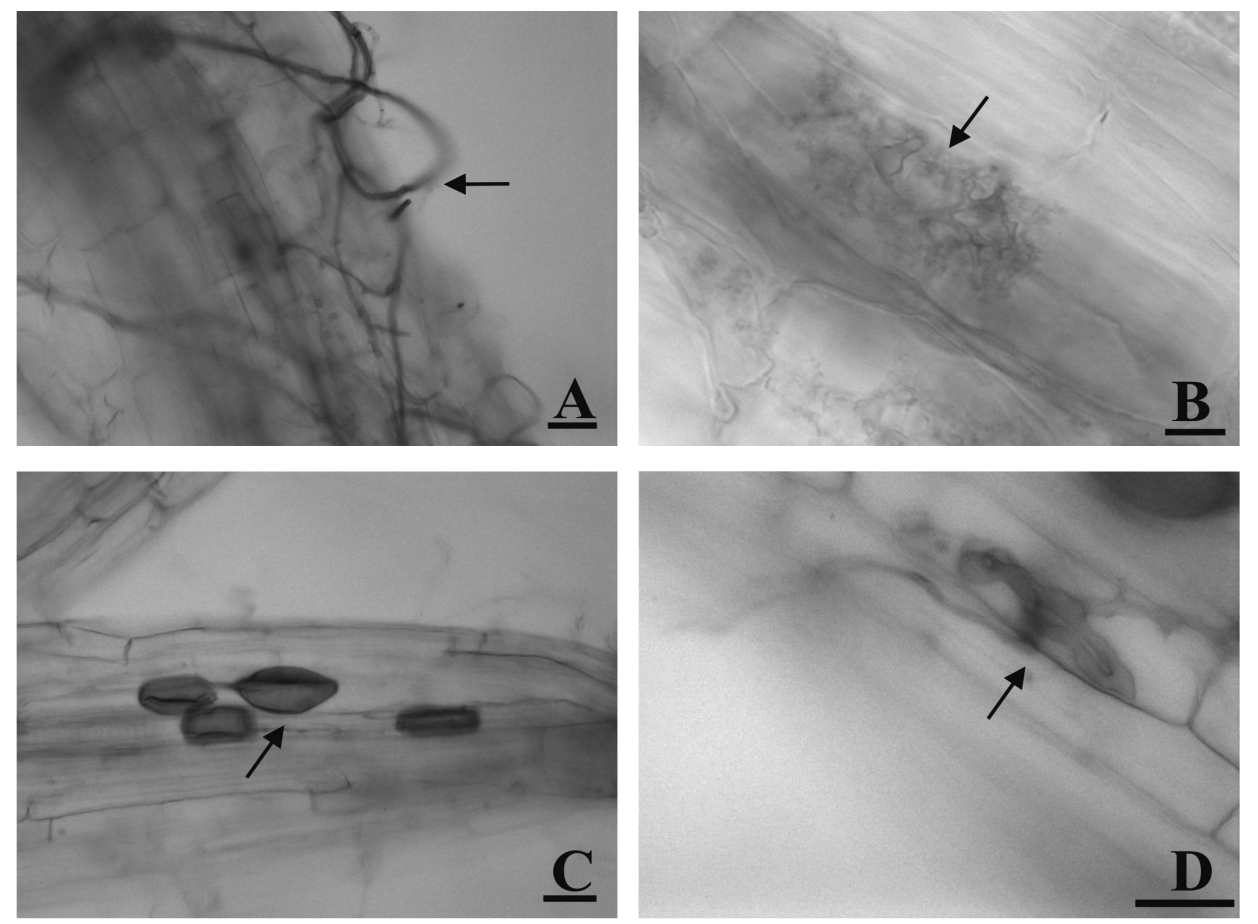

Figure 1 - Mycorrhizal colonization of Glomus intraradices in tomato (cultivar Platense) roots infected with Nacobbus aberrans. A) External hyphae (arrow); B) Arbuscule (arrow); C) Vesicles (arrow); D) Coil (arrow). Scale bar: A, C, and D: $50 \mu \mathrm{m}$; B: $10 \mu \mathrm{m}$.
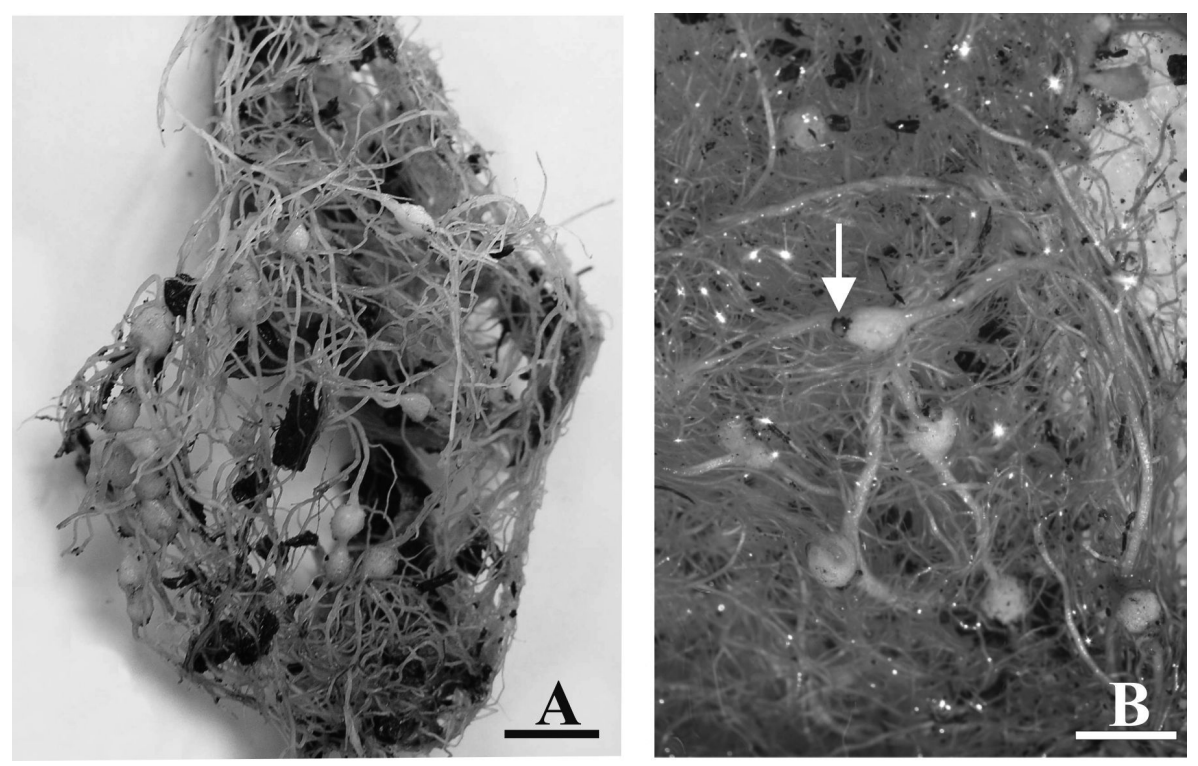

Figure 2 - Tomato roots parasitized by Nacobbus aberrans. A) Galled root system (NEM T0); B) Detail of galls with egg mass (arrow). Scale bar: A and B: $1 \mathrm{~cm}$.

\section{DISCUSSION}

Plant-parasitic nematodes have been traditionally managed with nematicides (Vos et al. 2012). Most of the chemical products used do not comply with current environmental regulations and soon they might be replaced with other management strategies of lower environmental impact (Harrier 
and Watson 2004). Improving the host tolerance through the association with mycorrhizal fungi seems to be a promising option.

In the present work, the application of $G$. intraradices at transplanting promoted the increase of aerial and root biomass of tomato, even in the presence of $N$. aberrans. An increase in biomass was observed in tomato inoculated with $G$. etunicatum Becker and Gerd. and Gigaspora margarita Becker and Hall, and parasitized with $M$. javanica (Treub) Chitwood (Cofcewicz et al. 2001). A similar situation was observed with $G$. etunicatum in kiwi (Actinidia delicios Chev.), attacked by M. javanica (Verdejo et al. 1990). In the present work, pre-inoculation of tomato with AMF and three weeks later with $N$. aberrans did not promote plant biomass. AMF may increase productivity by enhancing the plant resource uptake when competing with soil pathogens (Schnitzer et al. 2011). In the plants of the last treatment (AMF T0 + NEM T3), AMF was less time in contact with $N$. aberrans. Hence, AMF would not be able to increase resource availability to host, affecting biomass increase.

The percentage of mycorrhizal colonization can increase or decrease in the presence of plantparasitic nematodes (Roncadori 1997), depending on the arbuscular mycorrhizal species involved (Waceke et al. 2001). Here, the two treatments inoculated with nematodes and AMF (T0 and T3) showed increase in mycorrhizal level with respect to AMF at T0. Meloidogyne incognita (Kofoid and White) Chitwood, also showed an increase in the colonization of Acaulospora scrobiculata Trappe in tomato (Da Silva Sousa et al. 2010), of G. mosseae (Nicol. and Gerd.) Gerd. and Trappe in banana (Jaizme-Vega et al. 1997), and of $G i$. margarita in soybean (Glycine max (L.) Merrill) (Carling et al. 1989). Alban et al. (2013) observed a high percentage of AMF colonization in the roots of coffee (Coffea arabica L.) parasitized with M. exigua Göldi. According to these authors, if $\mathrm{AMF}$ and the nematode were simultaneously present in the soil, AMF colonized the roots before nematode infestation. Thus, coffee plants can regain the energy lost by the parasitic interaction, preventing the reduction in plant growth. However, in some situations, Glomus spp. colonization has been lower in the presence of Meloidogyne spp. on different hosts (Atilano et al. 1981; Waceke et al. 2001; Elsen et al. 2002). The presence of the nematode may interfere with nutrient flow between the root and the fungus, reducing AMF efficiency (Cofcewicz et al. 2001). Tomato was benefited by $G$. intraradices when inoculated at transplanting, through a $56 \%$ reduction in the number of galls induced by $N$. aberrans. A reduced number of galls was observed in the application of different fungus species on tomato roots attacked by $M$. incognita (Da Silva Sousa et al. 2010) and N. aberrans (Gardezi et al. 1995; Lax et al. 2011). Although there were no differences in the number of eggs produced by $N$. aberrans among treatments, a significant reduction $(69 \%)$ in the RF of the nematode at T0 was observed. A decrease in RF of different plantparasitic nematodes was detected in the presence of several AMF species (including $G$. intraradices) (Pinochet et al. 1998; Elsen et al. 2002; Talavera et al. 2002; Castillo et al. 2006; Lax et al. 2011; Vos et al. 2012). A reduction was observed in the final population of Pratylenchus vulnus Allen and Jensen in the roots of peach (Prunus persica L.) colonized by G. mosseae. This phenomenon was attributed to possible AMFinduced physiological changes in the roots, which would make the roots an unfavourable food source for the parasite (Pinochet et al. 1995).

The application of $G$. intraradices at transplanting significantly reduced the number of galls and RF of $N$. aberrans. However, in the plants mycorrhized and further inoculated with the nematode (AMF T0 + NEM T3), those parameters did not show significant differences from the respective control treatment (NEM T3). These results did not agree with the earlier studies considering $M$. incognita and $G$. mosseae on the same host (Talavera et al. 2001). The increased development of the root system three weeks after transplanting (regardless of presence or absence of mycorrhizal infection) might have affected the root penetration by juveniles, with the consequent reduction in the number of galls and final population of the nematode.

This work confirmed once again the usefulness of applying AMF at transplanting as a tool to manage $N$. aberrans populations on tomato. No tomato cultivars resistant to this nematode have been developed so far. AMF-tomato interaction might be an efficient control strategy in commercial production of this horticultural crop, especially under greenhouse conditions. In $N$. aberranscontaminated soils, the interaction would contribute to decrease the nematode population 
density, therefore reducing the damage produced by the parasite and increasing the crop yield.

\section{ACKNOWLEDGEMENTS}

This work was financially supported by Secretaría de Ciencia y Técnica (Universidad Nacional de Córdoba), Ministerio de Ciencia y Tecnología (province of Córdoba), and Consejo Nacional de Investigaciones Científicas y Técnicas (CONICET).

\section{REFERENCES}

Alban R, Guerrero R, Toro M. Interaction between a root knot nematode (Meloidogyne exigua) and arbuscular mycorrhizae in coffee plant development (Coffea arabica). Am J Plant Sci. 2013; 4: 19-23.

Atilano RA, Menge JA, Van Gundy SD. Interaction between Meloidogyne arenaria and Glomus fasciculatus in grape. J Nematol. 1981; 13: 52-57.

Azcón-Aguilar C, Barea JM. Arbuscular mycorrhizas and biological control of soil-borne plant phatogensan overview of the mechanisms involved. Mycorrhiza. 1996; 6: 457-464.

Borowicz VA. Do arbuscular mycorrhizal fungi alter plant-pathogen relations?. Ecology. 2001; 82: 30573068.

Cabello MN. Hydrocarbon pollution: its effect on native arbuscular mycorrhizal fungi (AMF). FEMS Microbiol Ecol. 1997; 22: 233-236.

Carling DE, Roncadori RW, Hussey RS. Interactions of vesicular-arbuscular mycorrhizal fungi, root-knot nematode, and phosphorus fertilization on soybean. Plant Dis. 1989; 73: 730-733.

Castillo P, Nico AI, Azcón-Aguilar C, Del Río Rincón C, Calvet C, Jimenez-Díaz RM. Protection of olive planting stocks against parasitism of root-knot nematodes by arbuscular mycorrhizal fungi. Plant Pathol. 2006; 55: 705-713.

Cofcewicz ET, Medeiros CAB, Carneiro RMDG, Pierobom CR. Interação dos fungos micorrízicos arbusculares Glomus etunicatum e Gigaspora margarita e o nematóide das galhas Meloidogyne javanica em tomateiro. Fitopatol Bras. 2001; 26: 6570.

Costilla MA, González de Ojeda S, Hasselrot de Gomez T. Contribución al estudio del falso nematodo del nudo Nacobbus aberrans. Nematropica. 1977; 7: 7-8.

Da Silva Sousa C, Fermino Soares AC, Coimbra JL, Da Silva Garrido M, Da Silva Machado G. Fungos micorrízicos arbusculares no controle de Meloidogyne incognita em mudas de tomateiro. Rev Caatinga. 2010; 23: 15-20.
Doucet ME, Lax P. El género Nacobbus Thorne \& Allen, 1944 en Argentina. 6. La especie N. aberrans (Thorne, 1935) Thorne \& Allen, 1944 (Nematoda: Tylenchida) y su relación con la agricultura. An Acad Nac Agronomía Vet. 2005; 59: 5-45.

Elsen A, Declerck S, De Waele D. Effects of Glomus intraradices on the reproduction of the burrowing nematode (Radopholus similis) in dixenic culture. Mycorrhiza. 2001; 11: 49-59.

Elsen A, Declerck S, De Waele D. Effect of three arbuscular mycorrhizal fungi on root-knot nematode (Meloidogyne spp.) infection of Musa. Infomusa. 2002; 11: 21-23.

Elsen A, Declerck S, De Waele D. Use of root organ cultures to investigate the interaction between Glomus intraradices and Pratylenchus coffeae. Appl Environ Microbiol. 2003; 69: 4308-4311.

Gardezi AK, Zavaleta-Mejía E, Garcia R, Ferrera CR, Perez CA. Efecto de endomicorrizas sobre la infección de Nacobbus aberrans en jitomate (Lycopersicon esculentum). Memorias XXII Congreso Nacional de Fitopatología, Guadalajara, México. 1995; pp. 146-148.

Gerdemann JW, Nicolson TH. Spores of mycorhizal Endogone species extracted from soil by wet sieving and decanting. Trans Brit Mycol Soc. 1963; 46: 235244.

Giovannetti M, Mosse B. An evaluation of techniques for measuring vesicular arbuscular mycorrhizal infection in roots. New Phytol. 1980; 84: 489-500.

Gómez L, Rodríguez MG, De la Noval B, Miranda I, Hernández MA. Interacción entre el Ecomic ${ }^{\circledR}$ y una población cubana de Meloidogyne incognita en tomate. Rev Protección Veg. 2008; 23: 90-98.

Graham JH, Menge JA. Influence of leaf phosphorus on take-all disease of wheat. Phytopatology. 1982; 72: 95-98.

Harrier LA, Watson CA. The potential role of arbuscular mycorrhizal (AM) fungi in the bioprotection of plants against soil-borne pathogens in organic and/or other sustainable farming systems. Pest Manag Sci. 2004; 60: 149-157.

Hussey RS, Barker KR. A comparation of methods of collecting inocula of Meloidogyne spp., including a new technique. Plant Dis Rep. 1973; 57: 1025-1028.

Infostat. Programa de análisis estadísticos. Cátedra de estadística. Facultad de Ciencias Agropecuarias, Universidad Nacional de Córdoba. 2001.

Jaizme-Vega MC, Tenoury P, Pinochet J, Jaumot M. Interactions between the root-knot nematode Meloidogyne incognita and Glomus mosseae in banana. Plant Soil. 1997; 196: 27-35.

Jenkins WR. A rapid centrifugal-flotation technique for separating nematodes from soil. Plant Dis Rep. 1964; 48: 692 . 
Karssen G, den Nijs LJMF. Diagnostic protocols for regulated pest: Nacobbus aberrans. EPPO Bulletin. 2001; 3: 71-77.

Lax P, Becerra AG, Soteras F, Cabello M, Doucet ME. Effect of the arbuscular mycorrhizal fungus Glomus intraradices on the false root-knot nematode Nacobbus aberrans in tomato plants. Biol Fertil Soils. 2011; 47: 591-597.

Manzanilla-López RH, Costilla MA, Doucet M, Franco J, Inserra RN, Lehman PS, et al. The genus Nacobbus Thorne \& Allen, 1944 (Nematoda: Pratylenchidae): systematics, distribution, biology and management. Nematropica. 2002; 32: 149-227.

Morandi D. Ocurrence of phytoalexins and phenolic compounds in endomycorrhizal interactions, and their potencial role in biological control. Plant Soil. 1996; 185: 241-251.

Phillips JM, Hayman DS. Improved procedures for clearing roots and staining parasitic and vesiculararbuscular mycorrhizal fungi for rapid assessment of infection. Trans Brit Mycol Soc. 1970; 55: 158-161.

Pinochet J, Calvet C, Camprubi A, Fernandez C. Growth and nutritional response of Nemared peach rootstock infected with Pratylenchus vulnus and the mycorrhizal fungus Glomus mosseae. Fundam Appl Nematol. 1995; 18: 205-210.

Pinochet J, Camprubí A, Calvet C, Fernández C. Inducing tolerance to the root-lesion nematode Pratylenchus vulnus by early mycorrhizal inoculation of micropropagated Myrobalan $29 \mathrm{C}$ plum rootstock. J Amer Soc Hort Sci. 1998; 123: 342-347.

Roncadori RW. Interactions between arbuscular mycorrhizas and plant parasitic nematodes in agroecosystems. In: Gange, A. C., Brown, V. K. Multitrophic interactions in terrestrial systems: $36^{\text {th }}$ Symposium of the British Ecological Society. Blackwell, Oxford, England. 1997; pp. 101-113.

Schnitzer SA, Klironomos JN, HilleRisLambers J, Kinkel LL, Reich PB, Xiao K, et al. Soil microbes drive the classic plant diversity-productivity pattern. Ecology. 2011; 92: 296-303.
Sher SA. Revision of the genus Nacobbus Thorne and Allen, 1944 (Nematoda: Tylenchoidea). J Nematol. 1970; 2: 228-235.

Shreenivasa KR, Krishnappa K, Ravichandra NG. Interaction effects of arbuscular mycorrhizal fungus Glomus fasciculatum and root-knot nematode, Meloidogyne incognita on growth and phosphorous uptake of tomato. Karnataka J Agric Sci. 2007; 20: 57-61.

Talavera M, Itou K, Mizukubo T. Reduction of nematode damage by root colonization with arbuscular mycorrhiza (Glomus spp.) in tomatoMeloidogyne incognita (Tylenchida: Meloidogynidae) and carrot-Pratylenchus penetrans (Tylenchida: Pratylenchidae) pathosystems. Appl Entomol Zool. 2001; 36: 387-392.

Talavera M, Itou K, Mizukubo T. Combined application of Glomus sp. and Pasteuria penetrans for reducing Meloidogyne incognita (Tylenchida: Meloidogynidae) populations and improving tomato growth. Appl Entomol Zool. 2002; 37: 61-67.

Verdejo S, Calvet C, Pinochet J. Efecto de la micorrización en kiwi infestado por los nematodos Meloidogyne hapla y M. javanica. Bol San Veg Plagas. 1990; 16: 629-624.

Vos C, Geerinckx K, Mkandawire R, Panis B, De Waele D, Elsen A. Arbuscular mycorrhizal fungi affect both penetration and further life stage development of root-knot nematodes in tomato. Mycorrhiza. 2012; 22: 157-163.

Waceke JW, Waudo SW, Sikora R. Response of Meloidogyne hapla to mycorrhiza fungi inoculation on pyrethrum. Afr J Sci Technol. 2001; 2: 63-70.

Wang B, Qiu YL. Phylogenetic distribution and evolution of mycorrhizas in land plants. Mycorrhiza. 2006; 16: 299-363.
Received: July 24, 2013; Accepted: April 22, 2014. 